representations from the sugar industry and 40 ambassadors from sugar producing countries who had been alerted by the industry.

A delay in the introduction of regulations on salt in Britain is perhaps the best that salt producers can expect. Elsewhere they have already lost the battle. The United States departments of agriculture and health have recently recommended a daily average salt intake of no more than $6 \mathrm{~g}$ for the general population ${ }^{16}$ despite representations from the Salt Institute and other bodies. Scandinavian countries have also adopted lower salt programmes. In Finland doctors only receive full reimbursement for antihypertensive drugs if they have given patients a six month trial of weight loss, alcohol restriction, and salt reduction (J Huttunen, personal communication).

But delay has its cost, to commercial interests as well as the public's health. While the Salt Institute fights, other players in the food industry are changing. Many manufacturers have already diversified into low salt products, while others such as Heinz have been reducing the salt content of their products. The sodium content of 100 American foods monitored by the Center for Science and the Public Interest has fallen by $10-15 \%$ over the past 12 years. ${ }^{17}$

Despite these trends, governments have a tough job ahead. The world's food and soft drink industry spent over $£ 550 \mathrm{~m}$ on advertising in 1994, compared with less than $£ 5 \mathrm{~m}$ on promoting fresh fruit and vegetables. ${ }^{18}$ In Britain, basic cooking skills are in decline ${ }^{19}$ as processed foods make up more of the average diet. To counter these forces governments will need to invest substantial resources in health education. The British government should be congratulated on the achievements of the Health of the Nation. But if it is serious about reducing premature deaths from cancer and heart disease it will need to ignore the voices of vested interest and listen to the advice of its independent expert advisors.

FIONA GODLEE

London WC1H 9JR Assistant editor, $B M \mathcal{F}$

1 National Research Council, Committee on Diet and Health, Food and Nutrition Board, Commission on Life Sciences. Diet and health: implications for reducing chronic disease. Washington, DC: National Academy Press, 1989.

2 Nutritional aspects of cardiovascular disease. Report of the Cardiovascular Review Group, Committee on Medical Aspects of Food Policy. London: HMSO, 1994.

3 Gregory J, Forster K, Tyler H, W iseman M. The dietary and nutritional survey of British adults. London: HMSO, 1990.

4 Intersalt Cooperative Research group. Intersalt: an international study of electrolyte excretion and blood pressure. Results for 24 hour urinary sodium and potassium. $B M F$ 1988;297: 319-28.

5 Elliott P, Stamler J, Nichols R, Dyer AR, Stamler R, Kesteloot H, et al for the Intersalt Cooperative Research Group. Intersalt revisited: further analyses of 24 hour sodium excretion and blood pressure within and across populations. BMF 1996;312:1249-53.

6 Hanneman RL. Intersalt: hypertension rise with age revisited. $B M 9$ 1996;312:1283-4.

7 Law M. Commentary: evidence on salt is consistent. BMF 1996;312:1284-5.

8 Stamler J, Elliott P, Dyer AR, Stamler R, Kesteloot H, Marmot $M$ for the Intersalt Steering and Editorial Committee. Commentary: Sodium and blood pressure in the Intersalt study and other studies-in reply to the Salt Institute. BMF 1996;312:1285-7.

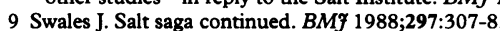

10 Secretary of State for Health. Health of the nation: a strategy for health in England. London: HMSO, 1992:54.

11 Blackburn H, Jacobs D. Sources of the diet-heart controversy: confusion over population versus individual correlations. Circulation 1984;70:775-80.

12 Marks K. Coming soon: what you can and can't eat. Daily Telegraph 1994 Aug 91994.

13 Anderson D. Take nanny's latest menu with a large pinch of salt. Daily Telegraph. 1994 Aug 9. 4 Department of Health. A progress report from the Nutrition Task Force on the action plan to achieve the Health of the Nation targets on diet and nutrition. London: DoH, 1996.

15 World Health Organisation. Diet, nutrition, and the prevention of chronic diseases. Geneva: WHO, 1990.

16 US Department of Agriculture, US Department of Health and Human Services. Dietary guidelines for Americans. 4th ed. Washington, DC: US Government Printing Office, 1995.

17 Jacobson MF, Liebman BF. Sodium in processed foods. Am f Clin Nutrition 1996:63:138.

18 Dibb SE, Castell A. Easy to swallow, hard to stomach. London: National Food Alliance, 1995.

19 Caraher M, Dixon P, Lang T. Buying eating and cooking food: a review of the national data set on food attitudes, skills and behavioural change. London: Health Education Council, 1996.

\title{
Salt and blood pressure revisited
}

\section{How much more evidence do we need?}

The relation between salt intake and blood pressure is no news to the food industry, nor to the expert committees in the United States, Norway, and elsewhere recommending reductions in daily intake of salt to about $100 \mathrm{mmol}$ sodium or less. ${ }^{12}$ However, with three quarters of the presently consumed salt well hidden in processed food, there is little that people can do to influence their intake. Thus, any attempts to influence the amount of salt in food must be directed at the food industry.

Hard data are now accumulating to give substance to the debate, most notably the Intersalt study, the first report of which was published in the $B M \mathcal{F}$ in $1988 .^{3}$ This cross sectional study of 10074 men and women with a broad age span was designed to describe the association between urinary excretion of sodium chloride (as a measure of salt intake) and blood pressure. After adjustments for body mass index, alcohol intake, sex, and age, it showed that a reduction in sodium intake of $100 \mathrm{mmol} / \mathrm{day}$ would reduce systolic and diastolic blood pressures by $2.2 \mathrm{~mm} \mathrm{Hg}$ and $0.1 \mathrm{~mm} \mathrm{Hg}$ respectively. This was based on individual data and was lower than expected from previous studies. ${ }^{4}$ But there was more to Intersalt than this. The study also had an ecological design that allowed the slope of the blood pressure curve to be estimated at different ages and different levels of sodium intake. This showed that increasing intake of sodium chloride by 100 $\mathrm{mmol} /$ day would increase systolic blood pressure by $10 \mathrm{~mm}$ $\mathrm{Hg} 30$ years later. Was this true? Did Intersalt reflect the real relation between salt and blood pressure, and why were the individual results so much weaker than the ecological findings?
In this issue of the $B M \mathcal{F}$ (p 1249) the Intersalt researchers present updated results for the relation between sodium excretion and blood pressure. ${ }^{5}$ These results are more robust than those in their first report. A striking finding is that the association between sodium excretion and blood pressure is stronger when body mass index is not adjusted for. The most likely explanation for this finding is that body mass index, which correlates with sodium excretion, is measured more accurately than sodium excretion and will therefore emerge as the strongest explanatory variable in a multiple regression analysis. ${ }^{6}$ That sodium excretion is the critical factor is also strongly suggested by data from the three Chinese Intersalt collaborating centres, which reported low body mass indexes but some of the strongest associations between sodium excretion and blood pressure, and some of the highest rises in blood pressure.

\section{Causal relation is difficult to demonstrate}

The magnitude of the effect of sodium excretion on blood pressure in this updated analysis is similar in the analyses within and across populations. This is comforting, even if the lack of effect on diastolic blood pressure in the population analysis when body mass index is adjusted for remains unexplained. A major reason for the stronger association between sodium excretion and blood pressure in the updated analysis than in the first report is a more complete correction for regression dilution bias, a correction which is warranted when variables are measured with error. 
The design and updated results of Intersalt may still fail to convince sceptics of a causal relation between salt intake and blood pressure, and some of the difficulties in demonstrating an association should therefore be emphasised. These include the measurement of salt intake, which is notoriously inaccurate for individuals, and the range of variation, which may be too narrow within a population compared with the large variation between individuals. The Intersalt study does not have the perfect design to overcome these difficulties, and on its own it cannot answer the question as to whether high salt intake causes high blood pressure. But until someone sets up a 30 year longitudinal study to monitor sodium chloride intake and blood pressure prospectively in a sufficiently large population, this hybrid cross sectional, within population and cross population, ecological study is likely to be the only feasible epidemiological design.

The updated version of Intersalt provides robust results that are in concert with other studies, including experiments on animals and clinical trials. ${ }^{7}$ A recent study on chimpanzees showed that adding $100 \mathrm{mmol}$ of sodium a day to their food increased their systolic blood pressure by $12 \mathrm{~mm} \mathrm{Hg}$. Blood pressure rose further with further increases in sodium intake and fell when sodium supplementation was stopped. ${ }^{8}$ The Intersalt results must be viewed in the context of such existing evidence suggesting a causal relation between salt intake and blood pressure. Whether the evidence is strong enough to warrant the reductions in salt recommended by the authors is, as always, a question of judgment. But useful clinical and public health actions have been undertaken on much weaker evidence.

DAG S THELLF Professor

Centre for Epidemiologic Research,

Institute of Community Medicine,

University of Oslo,

Oslo N-0318, Norway

1 US Department of Health and Human Services. Health people 2000: National health promotion and disease prevention objectives (summary report). Washington: Government Printing Office, 1991. (DHHS Publication No (PHS) 91-50213.)

2 The National Nutrition Council. Dietary recommendations. Oslo: NNC, 1989.

3 Intersalt Cooperative Group. Intersalt: an international study of electrolyte excretion and blood Intersalt Cooperative Group. Intersalt: an international study of electrolyte excretion and
pressure. Results for 24 hour sodium and potassium excretion. $B M Y$ 1988;297:319-28.

4 Frost CD, Law MR, Wald NJ. By how much does dietary salt reduction lower blood pressure? I: Analysis of observational data within populations. BMF 1991;302:815-9.

5 Elliott P, Stamler J, Nichols R, Dyer AR, Stamler R, Marmot M, et al. Intersalt revisited: further analyses from the Intersalt study on 24-hour sodium and blood pressure. $B M F$ 1996;312:???-

6 Dyer AR, Elliott P, Shipley M, Stamler R, Stamler J on behalf of the Intersalt Cooperative Research Group. Body mass index and associations of sodium and potassium with blood pressure in Intersalt. Hypertension 1994;23:729-36.

Law MR, Frost CD, Wald NJ. By how much does dietary salt reduction lower blood pressure. $B M f$ 1991;302:819-24.

8 Denton D, Weisinger R, Mundy NI, Wickings EJ, Dixson A, Moisson P, et al. The effect of increased salt intake on blood pressure of chimpanzees. Nature Medicine 1995;1:1009-16.

\title{
Whose data are they anyway?
}

\author{
Raw data from research on patients should be available, anonymised, to whoever wants them
}

\author{
"I like taking part in studies because it's for the greater \\ good, like giving blood."1
}

As reports of medical research show, there are almost no limits to what patients will put up with if they believe that their actions may benefit others. Seemingly, no questionnaire is too probing, no programme of clinic visits and tests too gruelling, and no drug too vile to stop patients volunteering for research.

Yet much of their goodwill is wasted. Many more research projects are begun than are completed, many more projects are completed than are written up, and many more papers are written up than are published. Of those that are published many are of poor quality, ${ }^{2}$ and few provide their raw data in a form that readers could use to check the authors' claims. Patients could justifiably argue that they are being sold short, given the inconvenience and risk that research often entails.

Access to raw data, and their interpretation, lie at the heart of the latest skirmish in the salt wars, which dominate this week's $B M F$. The president of the Salt Institute argues that "the entire Intersalt database... must be made available in its entirety to independent third parties for a thorough re-evaluation." ${ }^{3}$ Intersalt's researchers respond that they have done the further analyses suggested by the Salt Institute only to see the results either misused or ignored. ${ }^{4}$

Intersalt has hardly been sparing with its data: an appendix accompanying the original paper gave 27 columns of data for each of the 52 population samples. Subsequently, an issue of the fournal of Hypertension devoted to the study carried 38 appendix tables, with 20 columns of data each. Further data have been published in peer reviewed journals. In addition, Intersalt researchers have said they are willing to do any scientifically sound and practically feasible further analyses proposed by the Salt Institute.

But what they will not do is hand over the raw Intersalt data. "As is customary in scientific investigation, raw data on individuals remain the confidential property of local investiga- tors, in this case the 52 investigators in 32 countries."4 Their justification is "the need to preserve the independence of scientific investigation, the integrity of the data, and the confidentiality of information on individuals."

It is time for the customs to change if these are the strongest arguments that can be mustered in their support. Firstly, truly independent scientific investigation does not exist. The best we can hope for is for authors to be explicit about their methods and candid about any other relevant interests-thus alerting us to possible biases. Secondly, data have no intrinsic integrity of their own, such that sharing them with someone else might lead to their corruption. Undoubtedly, misuse of data is one of the downsides of sharing, but it is a price worth paying. And as long as avenues exist for criticising subsequent analyses that are seriously flawed then no lasting harm need result.

\section{Researchers should share}

The need to maintain the confidentiality of individuals seems the strongest justification, but there's a way round that too. When patients are recruited into studies their consent should be obtained for the sharing of their data with other researchers. Researchers should go one step further-and guarantee to participants that they will make available anonymised data to anyone who asks for it, after they have published their main results. Patients should demand this guarantee as a condition of their participation.

Compelling arguments exist for sharing data; George Davey Smith listed several in a recent BMJ editorial (see box) ${ }^{6}$ To facilitate the process grant giving bodies could make funding conditional on willingness to share data. Clearing houses for shared data could be set up, thereby reducing the burden on primary researchers. Searchable registers of active and completed projects would help. Ethics committees could insist that protocols allow for data sharing, meaning that unpalatable findings could still see the light of day even if the original 